\title{
CORRECTION
}

\section{Correction to: Heat shock protein 90 inhibitor attenuates renal fibrosis through degradation of transforming growth factor-b type II receptor}

Hyunjin Noh, Hyun J. Kim, Mi R. Yu, Wan-Young Kim, Jin Kim, Jung H. Ryu, Soon H. Kwon, Jin S. Jeon, Dong C. Han and Fuad Ziyadeh

(c) The Author(s), under exclusive licence to United States and Canadian Academy of Pathology 2021

Laboratory Investigation (2022) 102:212; https://doi.org/10.1038/s41374-021-00705-3

Correction to: Laboratory Investigation https://doi.org/10.1038/

labinvest.2012.127, published online 10 September 2012

The original version of this article unfortunately contained a mistake. Beta-actin for Fig. 1a left panel is incorrect. The revised figure can be found below. The authors apologize for the error.

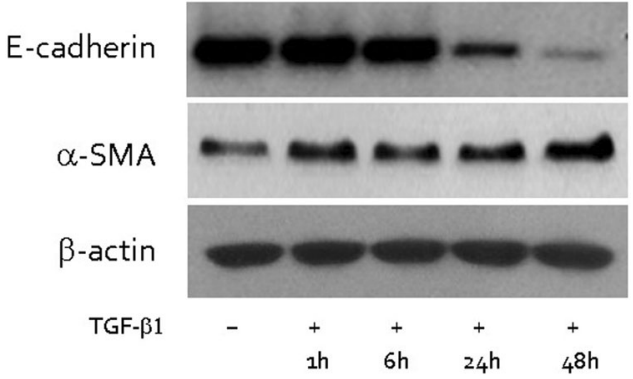

